\title{
A grande estratégia do Império português: D. Luís da Cunha e as origens do reformismo ilustrado luso-brasileiro
}

The great strategy of the Portuguese empire: D. Luis da Cunha and the origins of the Luso-Brazilian enlightened reformism

\author{
Nelson Mendes Cantarino(1) \\ Fernando Ribeiro Leite Neto (2) \\ (1) Universidade Estadual de Campinas \\ (2) Instituto de Ensino e Pesquisa (INSPER)
}

\begin{abstract}
The article presents the reform proposals of D. Luís da Cunha (1662-1749) in the context of the transition from the seventeenth century to the eighteenth century in Portugal. For this, the article begins with the contextualization of the changes in the balance of power and political thought associated with the emergence of Great Britain as the centralizing Empire of the events of the 18th century. In this transition, important intellectual developments are in process, for example the rise of the Political Economy as an autonomous discipline and its relevance to the management of the interests of the Kingdom and the Empire. It follows with the characterization of the proposed reforms made by D. Luís da Cunha which aimed at raising the relative power of Portugal. In this way, D. Luís enumerates the need to increase the population contingent both in the Kingdom and in the areas of the sea, to facilitate the flow of goods and coins, to reduce certain privileges and even to review the statutes of the Inquisition.
\end{abstract}

\section{Keywords}

Portugal, mercantilism, D. Luís da Cunha.

JEL Codes B11, B31.

\section{Resumo}

Este artigo apresenta as propostas de reformas de D. Luís da Cunha (1662-1749) no contexto da transição do Seiscentos para o Setecentos no Império português. Para tanto, o artigo principia com a contextualização das mudanças no balanço de poder e no pensamento político associadas à emergência da Grã-Bretanha como Império centralizador dos eventos do século XVIII. Nessa transição importantes desdobramentos intelectuais estão em processo como, por exemplo, a ascensão da Economia Política como disciplina autônoma e sua relevância para a gestão dos interesses do Reino e do Império. Segue-se com a caracterização das reformas propostas por D. Luís da Cunha que visavam, em linha com a tradição mercantilista, elevar o poder relativo de Portugal. Dessa forma, D. Luís elenca a necessidade de incrementar o contingente populacional, seja no Reino, seja nos dominios de ultramar, facilitar os fluxos de mercadorias e de moedas, reduzir certos privilégios e, até mesmo, de rever os estatutos da Inquisição.

\section{Palavras-chave}

Portugal, mercantilismo, D. Luís da Cunha.

Códigos JEL $B 11, B 31$. 


\section{Introdução}

O alvorecer do século XVIII trouxe novos dilemas para Portugal. Com a consolidação do poder econômico e marítimo da Grã-Bretanha, uma questão central se impôs sobre a Coroa portuguesa. Como assegurar a segurança e a integridade imperial em uma situação na qual Lisboa deve posicionar-se frente a pressões das quais não tem autonomia de decisão? Nesse contexto, será que os portugueses criaram e seguiram uma estratégia para garantir a soberania e a integridade do Império em meio às turbulências que se desdobram entre a Revolução Gloriosa (1688) e a Guerra dos Sete Anos (1756-1763)?

A primeira observação que devemos fazer é que grandes estratégias nem sempre são agressivas nem implicam meramente atividades bélicas. Todas abrangem, todavia, as decisões de um determinado Estado sobre a sua segurança e supõem a integração de objetivos gerais políticos, econômicos e militares. As estratégias globais devem ser analisadas antes de tudo por seus custos políticos e econômicos e pelo uso da diplomacia, da aplicação da força e do uso de "incentivos", que podem ser subvenções, mercês e presentes. As estratégias mais eficazes fazem apenas o indispensável para derrotar e dissuadir aqueles que lhes ameaçam, recorrendo não apenas à dissuasão, mas também à propaganda e ao engano. ${ }^{1}$

Como estabelecer uma economia próspera capaz de permitir uma posição autônoma de Lisboa frente à competição entre os Estados modernos? Esses eram os objetivos de D. Luís da Cunha (1662-1749). Ministro plenipotenciário e embaixador, Cunha foi um observador astuto posicionado em cortes europeias de destaque: Londres, Haia e Paris, entre outras. Em suas missões escreveu memórias e pareceres comparando as políticas econômicas de outros poderes europeus com o potencial português, sempre buscando compreender como o comércio, a diplomacia e o poder militar podiam ser condensados em uma grande estratégia.

Este artigo objetiva reconstituir a abrangência das propostas de D. Luís da Cunha. Para tanto, em primeiro lugar, deve-se ter em mente o contexto de transformações no qual D. Luís estava escrevendo bem como os dile1 Acerca do conceito de grande estratégia, seus usos e exemplos, seguimos a abordagem de LUTTWAK (1976, 2009), apresentada em dois ensaios: "The Grand Strategy of the Roman Empire. From the First Century A. D. to the Third"; "The Grand Strategy of the Byzantine Empire". Para os dilemas estratégicos de uma monarquia ibérica na Idade Moderna a referência óbvia é o ensaio de PARKER (2000). 
mas que a Coroa portuguesa enfrentava. Essa é a temática da primeira parte do artigo. Depois, apresenta-se o contexto do reformismo ilustrado português no limiar do Setecentos e comenta-se o papel dos estrangeirados no debate intelectual do período. As propostas reformistas de D. Luís da Cunha são apresentadas na seção que antecede as considerações finais.

\section{A economia política, o aumento das tensões inter- nacionais e a autonomia de Lisboa}

(...) the Theory of Trade is a Princely Science, and the true Regulation of it the Key of Empire (WOOD, William. A Survey of Trade, 1718). ${ }^{2}$

O financiamento do poder estatal e a administração próspera de seus recursos são fundamentais para a manutenção da paz e da ordem pública, pois viabilizam as ações da autoridade constituída. $\bigcirc$ apaziguamento para disputas internas que a economia política - a administração pública dos encargos e necessidades do Estado - trouxe para as monarquias modernas, no entanto, acarretou uma visão do futuro como uma competição global entre Estados comerciais. Já para meados do século XVII, a interdependência da política com a economia, pela primeira vez, tornou-se o tópico central da teoria dos governos, pois ficou óbvio para os contemporâneos que o sucesso no comércio internacional era determinante para a manutenção militar e política dos Estados soberanos. Assim, a direção do processo econômico tornou-se política, direcionada pela autoridade pública e pelos grupos sociais que lhe davam sustentação. Estava implícita na política moderna a ideia de que a lógica do comércio estava interligada com a dinâmica da guerra. Esse é o contexto da Jealousy of trade, momento em que todo o globo transforma-se em um palco de disputas comerciais entre as potências europeias. ${ }^{3}$

2 WOOD apud ARMITAGE, 2009, p. 146.

3 HONT, 2005, p. 1-8. Immanuel Wallerstein chamou esses conflitos de "a luta no centro" - struggle in the core. Tais disputas visavam à apropriação do excedente comercial de áreas periféricas, sendo esse o capital primitivo para a elevação da renda dos países centrais e para o processo de industrialização da Inglaterra. $O$ autor divide essas lutas em três etapas distintas: a primeira delas, de 1651 a 1689 , tem hegemonia holandesa desafiada com êxito por ingleses e franceses; a segunda, de 1689 a 1763, delimita uma rivalidade ininterrupta entre Londres e Paris e, finalmente, a terceira etapa, de 1763 a 1815, conta com a derrota do esforço francês de frear uma hegemonia britânica irresistível. Para um estudo detalhado das duas primeiras etapas, cf. WALLERSTEIN, 1994. 
Essa mudança na perspectiva econômica do Estado baseia-se em movimentos concomitantes: a superação das guerras religiosas na França e ao resultado das revoluções políticas na Inglaterra seiscentista. Assim, após a resolução de conflitos internos, os franceses vão enfrentar o poder hegemônico dos espanhóis. Os ingleses, por sua vez, obtiveram sucesso no combate à primazia comercial dos holandeses. ${ }^{4}$

Não podemos esquecer o fato de que a guerra e a estratégia militar tornaram-se, cada vez mais, dispendiosas na Europa pós-Guerra dos 30 Anos (1618-1648). No alvorecer do século XVIII, a guerra havia se tornado extremamente onerosa, tanto pelo desenvolvimento de novas tecnologias militares, como pelo envolvimento das potências europeias em sucessivas guerras. O resultado foi a necessidade de manutenção de exércitos permanentes, treinados, abastecidos e prontos para entrar em combate, abandonando, assim, o velho costume de dispensar infantes ao final dos conflitos. ${ }^{5}$

Resolvidos os conflitos domésticos e estabelecido um novo status quo político, a Inglaterra passará a expandir seu aparato administrativo, que será responsável não apenas por seu território no Velho Mundo, mas também por seus súditos e suas colônias no além-mar. No auge de suas atividades expansionistas, os gastos do governo britânico passaram de cerca de 2 milhões de libras - valor médio de gasto em períodos de paz - para 150 milhões de libras, um aumento de aproximadamente 75 vezes. ${ }^{6}$

A solução da Coroa inglesa para essa pressão financeira foi mobilizar empréstimos particulares. Desde a Idade Média, os soberanos endividados recorriam à comunidade bancária internacional para financiar suas aventuras militares. Ao final do século XVII, no entanto, os mecanismos de captação de fundos tornaram-se muito mais diversificados e complexos, requerendo uma administração governamental igualmente complexa. Nesse contexto, os ingleses batizaram seu sistema de "Crédito Público" ou de "Dívida Nacional". Para a operação regular desse sistema, foi decisiva a fundação do Banco da Inglaterra nos anos de 1690, que passou a centralizar e a administrar a captação dos empréstimos, além de estimular a

4 Para o conflito entre franceses e espanhóis, ver ELLIOTT, 2008. Do mesmo autor, cf. Richelieu and Olivares (1984). Já em relação às disputas entre britânicos e holandeses, cf. ORMROD, 2003.

5 Ver PARKER, 2003.

6 Cf. POCOCK, 2003, p. 425. 
barganha de papéis do Tesouro nas bolsas de Londres e Amsterdã.

Assim, o status quo político britânico do período de prevalência Whig, que se estende da Revolução Gloriosa (1688-89) até meados do século XVIII, é baseado no Crédito Público (sustentação econômica), no Exército e na Marinha de Guerra permanentes (sustentação militar) e na patronagem do rei com o partido Whig no Parlamento (sustentação política). ${ }^{8}$

Juntos, a guerra e o comércio foram os motores do desenvolvimento econômico britânico. Entre justificativas ideológicas e a necessidade de compreender e de melhor administrar os resultados desse processo vemos o uso instrumental da economia política. De sua acepção original - o governo do Estado como uma grande Casa ${ }^{9}$ - as ideias econômicas vão servir para calcular e maximizar os benefícios da colonização das extensas áreas do ultramar.

$\mathrm{O}$ argumento apresentado até aqui não se afasta da visão que usualmente associa ideias econômicas ao mercantilismo e a um conjunto de concepções desenvolvidas, na prática, por ministros, juristas e comerciantes, com objetivo econômico, político e estratégico: o estabelecimento de Estados Nacionais centralizados. Partindo dessa interpretação, o receituário mercantilista estava baseado em um intenso protecionismo estatal e em uma ampla intervenção das Coroas na economia. Uma forte autoridade central era tida como essencial para a expansão dos mercados e para a proteção dos interesses comerciais dos mercadores locais. Sua aplicação variava, no entanto, conforme a situação do país, seus recursos e o modelo de governo vigente. Na Holanda, por exemplo, o poder estatal era subordinado às necessidades do comércio. Na Inglaterra e na França, por sua vez, a iniciativa econômica estatal estava relacionada aos interesses militares, geralmente agressivos em relação às outras potências europeias. Os mercantilistas, limitando sua análise ao âmbito da circulação de bens,

7 Segundo Wennerlind, a ideia de Crédito Público, desenvolvida durante a "English Financial Revolution" do período de 1620-1720, foi diretamente responsável pela dominância militar, política e econômica dos britânicos durante o século XVIII (WENNERLIND, 2011).

8 Os dois principais grupos políticos ingleses do período pós-revolucionário eram os Tories e os Whigs. Os primeiros defendiam que a balança constitucional deveria pender para o fortalecimento da autoridade do monarca. Já os Whigs eram o grupo que controlou o Parlamento e a política estatal britânica. Tal grupo defendia a liberdade dos súditos e uma ordem jurídica pró-interesses privados, com o Estado apoiando uma política comercial assertiva. Cf. POCOCK, 1999, p. 121-141.

9 A ideia de Casa está correlacionada ao caráter patrimonial do Estado, em que o soberano organiza seu poder político pelos mesmos princípios do exercício de seu mando doméstico. Essa abordagem, inspirada na obra de Max Weber (1864-1920), é desenvolvida em ELIAS, 2001, p. 66-84. 
aprofundaram o conhecimento de questões como balança comercial, taxas de câmbio e movimentos de dinheiro. ${ }^{10}$

Outra transformação fundamental foi a da própria concepção de mercado, agora baseada em noções do direito natural, estabelecidas nas primeiras décadas do século XVIII. Partindo do argumento de que Deus criou o mundo perfeito e bondoso, além da ideia de que tudo que há no mundo está submetido a leis naturais para proporcionar a conservação e a felicidade dos homens, acreditava-se que o plano divino só iria se realizar quando cada indivíduo agisse conscientemente para melhorar sua própria condição. O direito natural seria, então, um dos fatores responsáveis por colocar o homem no centro das especulações filosóficas e, consequentemente, pelo desenvolvimento de um novo espírito científico, que seria guiado pela racionalidade, principal instrumento utilizado pelos indivíduos para decifrar o mundo em que viviam sem recorrer a explicações transcendentais. Essa mudança de concepção de mundo origina um processo de secularização, sendo uma de suas características a emergência de diversas disciplinas intelectuais, cada uma com sua especialidade e, posteriormente, seus especialistas. ${ }^{11}$

Já a associação entre a história natural e o discurso econômico autônomo vem da vontade de se compreender o funcionamento material do mundo natural, que, cada vez mais, fazia-se presente no decorrer do século XVIII. Entre as motivações por trás do interesse público pelas novas ciências do mundo natural, podemos citar a utilidade e a aplicação delas na solução de problemas da vida real. Cria-se, então, uma estreita relação entre as ciências naturais e as questões de caráter econômico, pois várias concepções originariamente das ciências da natureza - como ordem, equilíbrio e regulação - são absorvidas pelo discurso econômico em formação. ${ }^{12}$

10 Cf. Heckscher (1983), devemos, entretanto, fazer algumas ressalvas a essa interpretação. Segundo Lars Magnusson, o mercantilismo deve ser abordado da forma em que surgiu historicamente: como uma literatura, um discurso acerca do comércio e da economia que apareceu no contexto nacional inglês, sendo adaptado posteriormente para outros contextos nacionais e intelectuais e para a política e economia do mundo real. Cf. MAGNUSSON (1994).

11 Hont e Ignatieff entendem a ideia de secularização, fundamentalmente, como a redução da influência das autoridades eclesiásticas e das crenças tradicionais da Igreja nos pensamentos ético, político e econômico, além da mudança de ênfase dos valores religiosos para os valores temporais. Para uma discussão da influência da secularização no surgimento das reflexões econômicas, cf. HONT; IGNATIEFF, 1983, p. 1-45.

12 Ao abordar o tema da autonomia do discurso econômico Margaret Schabas faz uma ressalva. Até meados do século XIX, os teóricos da economia política não consideravam seu objeto de estudo apartado das "ciências naturais". Não apenas os fenômenos econômicos 
A economia política torna-se, assim, mais complexa do que o ideário mercantil, por trazer para seu escopo de análise as relações econômicas entre os indivíduos e a tentativa de estabelecer leis que explicassem de forma abrangente essas relações. ${ }^{13}$ Tal processo de valorização do indivíduo também leva à primazia do econômico sobre a política pública. Trata-se, no entanto, de um movimento mais sutil, pois tem um viés filosófico e cultural, agregando a transição da hegemonia da ideia de glória - típica da Idade Média e do início da Idade Moderna - para a noção de interesse, fundamental para o controle das emoções pessoais (paixões) e reguladora de uma nova ordem política, em que a expansão econômica levaria bem-estar à maior parte da população. ${ }^{14}$

\section{Casa de Bragança e reforma institucional: enfrenta- mento das ameaças ao Reino e ao Império}

Para o Reino de Portugal e para os soberanos da Casa de Bragança, as últimas décadas do século XVII foram de luta por sua autonomia e por reconhecimento internacional. O período da Guerra da Restauração (1641$1668)^{15}$ foi de disputa nos paradigmas governativos da Coroa: como maximizar a eficiência das engrenagens do poder e do esforço de guerra contra inimigos nas fronteiras do Reino e do Império?

Com os Bragança, os tribunais régios passaram a ter predominância na estrutura de governação, servindo de contraponto ao modelo governativo de Madri, baseado principalmente em Juntas e Validos. ${ }^{16}$ Então novas instâncias governativas superiores foram criadas ou receberam novos regimentos, como o Conselho de Estado, o Conselho de Guerra, o Conselho

deveriam ser compreendidos por analogias aos fenômenos naturais, mas eram vistos como uma extensão da natureza. O discurso econômico era considerado parte da filosofia natural, e não uma ciência humana (SCHABAS, 2005).

13 Cf. DUMONT, 2000, p. 77-94.

14 O processo de transição entre o ideário da honra e da glória para o da conquista de benefícios materiais estritamente econômicos é analisado por HIRSCHMAN, 2002.

15 Uma ressalva ao argumento apresentado por nós é o trabalho de Fernando Dores Costa. Segundo Costa, o esforço militar português na Restauração não explicitou o aprimoramento das instâncias de governo portuguesas, muito menos estava baseado em uma doutrina militar coesa. Nossa perspectiva é realçar uma diferenciação com as práticas de governo estabelecidas em Madri. Ver COSTA, 2004.

16 Para as relações governativas entre Lisboa e Madri e suas distinções, cf. SCHAUB, 2001. 
Ultramarino e a Junta dos Três Estados. A gestão das políticas régias dava-se pelo diálogo e pelas disputas por influência entre esses conselhos superiores, que centralizavam a administração diplomática, militar, financeira e patrimonial da Coroa. Além disso, esses conselhos deviam responder e arbitrar demandas oriundas dos espaços periféricos do Império. ${ }^{17}$

Mas esse processo de reorganização das esferas de governança da monarquia portuguesa não foi unívoco. Ainda nos anos mais conturbados de guerra com os Habsburgos, o controle da governança da Casa Real e dos processos políticos da Coroa ficou a cargo de Luís Vasconcelos e Sousa, $3^{\circ}$ Conde de Castelo Melhor. Durante quase cinco anos completos (16621667) Castelo Melhor assumiu o cargo de Escrivão da Puridade, com uma gestão dos assuntos públicos próxima dos privados espanhóis. ${ }^{18}$

Percebemos, então, que diversos paradigmas governativos para a Coroa portuguesa ainda estavam em disputa em fins do século XVII. O modelo mercantilista de consolidação estatal avançará no reinado de D. João V, cuja longa duração (1706-1750) será o momento de atuação de D. Luís da Cunha. Ainda no início desse reinado alguns acontecimentos marcaram a percepção de que reformas governativas eram necessárias. A Guerra de Sucessão (1701-1714) pelo trono espanhol demonstrou que a doutrina militar portuguesa, um sucesso durante as lutas da Restauração, já não respondia às necessidades dos novos campos de batalha. Uma modernização era necessária, por exemplo, na escolha dos comandos militares, geralmente cedidos à primeira nobreza do Reino. Além disso, o processo de tomada de decisão em Lisboa passou a demandar maior agilidade, o que ficou demonstrado pelo novo prestígio que as Secretarias de Estado alcançam frente aos Conselhos e a outras esferas de decisão coletivas. ${ }^{19}$

Outra mudança significativa foi o papel de destaque que a diplomacia de representação ocupou na política da Coroa portuguesa. Muita ênfase é dada nas relações de Lisboa com a Santa Sé, com os Bragança demandando paridade de tratamento com as outras grandes potências católicas no seu

17 LOUREIRO, 2014, pp. 44-57.

18 DANTAS, t. 25, 2012, pp. 171-186.

19 Aqui há uma polêmica entre os estudiosos do período: por mais que os Secretários de Estado fossem cada vez mais demandados e estivessem mais presentes aos despachos régios, sua normatização e o estabelecimento de suas prerrogativas formais se deram pelo alvará de 28/06/1736, com a criação das Secretarias de Estado dos Negócios Interiores do Reino, dos Negócios da Marinha e dos Domínios Ultramarinos e dos Negócios Estrangeiros e da Guerra. No entanto, a adoção da designação de ministros e secretários de Estado só ocorreu, ao que parece, em 1760 durante o pombalismo. Cf. MONTEIRO, 2001, pp. 961-987. 
relacionamento com o Papado, objetivo atingido com o título de Sua Majestade Fidelíssima concedido aos monarcas portugueses pelo Papa Bento XIV em 1748. Mas nas primeiras décadas do século XVIII a diplomacia portuguesa também foi atuante em congressos que buscavam pacificar $\mathrm{O}$ continente europeu e estabelecer um novo status quo dinástico e o reconhecimento de novas dimensões para conceitos como o de limite - agora significando limite de poder / soberania: a partir do Congresso de Utrecht (1713-1715) a contradição entre a crença no cosmopolitismo e a necessidade de definir fronteiras será arbitrada pela diplomacia e pelos rituais do cerimonial diplomático.

\section{D. Luís da Cunha e as origens do reformismo ilustra- do português}

O poder próprio em que se funda a conservação de Portugal, ou são as forças interiores do Reino ou as exteriores das Conquistas (...) porque, posto que o poder militar conste e se componha de gente, armas, munições, cavalos, etc., tudo isto se reduz a dinheiros (Padre Antônio Vieira). ${ }^{20}$

Possivelmente, o homem que melhor compreendeu a nova conjuntura internacional, suas disputas e seu novo balanço de poder foi D. Luís da Cunha (1662-1749). ${ }^{21}$ Servindo como representante diplomático nas principais cortes da Europa, D. Luís viveu parte de sua vida no estrangeiro, onde entrou em contato com as novas ideias do século e participou ativamente, ou como observador, de grandes conferências diplomáticas, como as que finalizaram os acordos de paz de Utrecht (1713-1715).

Assim, podemos colocá-lo, ao lado de Luís António Verney (17131792), como um dos arquétipos dos estrangeirados, letrados que, à sombra do Estado, tentavam adaptar as ideias e a epistemologia do novo século ao contexto português. ${ }^{22}$ Defensor da razão de Estado, ${ }^{23}$ foi hábil em mon-

20 Proposta feita a El-Rei D. João IV em que se lhe representa o miserável estado do Reino e a necessidade que tinha de admitir os judeus mercadores que andavam por diversas partes da Europa (VIEIRA, 1995, pp. 291-292).

21 Para os dados biográficos de D. Luís da Cunha e sua carreira diplomática, cf. as seguintes referências: CLUNY, 1999; CUNHA, 2001; FURTADO, 2010, p. 373-400.

22 Para o debate historiográfico em torno dos estrangeirados e seu papel na difusão da cultura ilustrada em Portugal, ver MIRANDA, 1990/1991, p. 35-70; cf. também CARNEIRO; SIMÕES; DIOGO, 2000, p. 591-619.

23 O diplomata defende a razão de Estado com ressalvas, como podemos perceber pelo $16^{\circ}$ Conselho pessoal a Marco Antonio de Azevedo Coutinho: "Não se deixe V. S.a seduzir do 
tar uma rede de poder por meio de suas opiniões e conselhos, difundidos através de missivas, memórias e instruções. Em especial, dois desses textos esboçam, com clareza, sua visão da geopolítica portuguesa e os caminhos que deveriam ser trilhados por aqueles que assumissem as rédeas do poder em Lisboa: as Instruções políticas, redigidas para seu pupilo Marco Antônio de Azevedo Coutinho (1688-1750), e seu Testamento político, encaminhado ao futuro rei D. José I (1714-1777). ${ }^{24}$

O primeiro dos textos citados aborda diretamente o tripé estratégico da prosperidade econômica, da força militar e da liderança política. A primeira preocupação que $\mathrm{D}$. Luís da Cunha externa ao seu discípulo é o fraco equilíbrio entre os interesses portugueses e os de seus vizinhos espanhóis. Era prioridade, então, diminuir as vantagens comparativas que o governo de Madri exibia frente ao poder dos secretários de Estado em Lisboa, pois somente dessa maneira a soberania política do Reino de Portugal estaria definitivamente assegurada.

O raciocínio de D. Luís segue a lógica das ideias mercantilistas: as vantagens espanholas estavam baseadas em sua população mais numerosa, em sua maior extensão geográfica - tanto no Velho, como no Novo Mundo - e no maior poderio econômico e militar que seus territórios e sua população propiciavam. O fato de o território português na Europa ser diminuto poderia ser contornado com a consolidação da soberania portuguesa sobre os domínios do além-mar. Tais domínios deveriam ser assegurados pela assinatura de tratados que legalizassem a posse das terras já sob controle português e pelo estabelecimento de fronteiras naturais que viabilizassem a defesa militar e o controle econômico. ${ }^{25}$

Já em relação à defasagem populacional, era preciso estancar as "sangrias" que levavam ao despovoamento do Reino e à ociosidade. ${ }^{26}$ Seguro

que comumente se chama razão de Estado, entendo-a no seu verdadeiro sentido, e não no que ela se pratica, que no fundo não é a razão de Estado, mas sem-razão do príncipe, o qual, com o pretexto de segurar o que possui, procura usurpar o que lhe não toca." Cf. CUNHA, 2001, p. 201.

24 CUNHA, 2001; Testamento Político de D. Luís da Cunha (1748) (1976). Segundo Abílio Diniz Silva, as Instruções políticas foram redigidas em sua forma final no ano de 1736 . No entanto, várias das ideias apresentadas ali já haviam aparecido na correspondência de D. Luís nas décadas anteriores.

25 Objetivo perseguido pelo Tratado de Madri celebrado em 1750 e pelos acordos de fronteira ajustados posteriormente pelas duas Coroas Ibéricas. Cf. CORTESÃO, 2006.

26 A preocupação de D. Luís com a questão do despovoamento do Reino é tipicamente mercantilista. Uma grande população produtiva era fundamental para manter os salários reduzidos, para desenvolver uma agricultura de abastecimento e para formar os quadros da 
pelo fato de estar servindo no exterior e com o conhecimento de que sua Instrução circularia entre um público restrito, D. Luís da Cunha não temeu denunciar, às vezes com comentários heterodoxos, as causas do problema.

O grande número de conventos e mosteiros existentes no Reino era a primeira sangria a ser estancada. Esse fator era culpado por entravar o investimento produtivo, devido às doações realizadas pelos devotos. Em muitos casos, os donativos tornavam-se bens inalienáveis das comunidades religiosas, que possuíam vastas extensões de terra ociosas ou que produziam apenas para a subsistência ou lucro dos religiosos. Assim, os claustros estavam repletos de homens que poderiam ser úteis na administração do Império e no setor produtivo. Os recolhimentos femininos também eram prejudiciais aos interesses do Reino, pois nesse processo ficavam empatados dotes necessários como capitais e mulheres sem a mínima vocação religiosa. ${ }^{27}$

Nesse mesmo sentido, a situação dos recolhimentos nas conquistas era ainda mais preocupante. Essa segunda sangria poderia levar à perda do Império, seja pela falta de homens na administração civil e militar ou "onde se necessita de gente que trabalhe nas suas plantações e nas suas minas, para aumentar o seu comércio", seja pelos gastos elevadíssimos de manutenção dos celibatários. No entanto, D. Luís deixou claro que a solução deve abranger tanto o Reino como o ultramar, pois todos os territórios da monarquia enfrentavam o mesmo problema. ${ }^{28}$

marinha mercante e de guerra. A produção agrícola doméstica incentivava a desoneração da balança comercial pela diversificação dos produtos para exportação e pela redução das importações de alimentos. "O primeiro que me representa, é o de evitar que o corpo do Estado seja em tantas veias, e por tantos modos sangrado; porque sendo povo o seu sangue, segue-se que ele se enfraquece todas as vezes que se lhe diminui; e assim a boa razão nos deve persuadir que os muitos homens são as verdadeiras minas de um Estado, porque sempre produzem e nunca se esgotam. Mas que homens, meu Filho? Homens que trabalhem nas terras que por falta deles ficam incultas; homens que por serem muitos, se apliquem a tudo o que lhes pode dar de comer, porque não há algum que queira morrer de fome, e enfim, homens que sirvam ao príncipe e à república por terra e por mar, com utilidade do comércio." Cf. CUNHA, 2001, p. 218.

27 Nesse trecho específico da instrução, D. Luís aborda dois temas retomados no governo do futuro Marquês de Pombal: a necessidade de reforma das Ordens Regulares e a grande influência dos jesuítas, os "anfíbios da religião", na vida cultural portuguesa. Cf. CUNHA, 2001, pp. 218-223.

28 Nessa passagem de sua instrução, D. Luís dá vários exemplos irônicos para ressaltar os abusos da vida nos recolhimentos: "Mas que importará que no Brasil se não multipliquem os conventos, se de lá se mandam os filhos e filhas a fazer frades e freiras a Lisboa. Eu me lembro de que certo brasileiro natural da Bahia, muito rico, meteu no convento da Esperança seis filhas que tinha, dando por cada uma seis mil cruzados de dote, porque ouvia que no dito convento não entravam senão pessoas da primeira condição. Tal é a vaidade daquela gente, $\mathrm{e}$ 
O diagnóstico da terceira sangria é uma das passagens mais polêmicas dos escritos de D. Luís da Cunha. O alvo de sua crítica é a Inquisição ${ }^{29}$ e, em tal passagem, escutamos os ecos do protesto do Padre Antônio Vieira (1608-1697), que, na conjuntura histórica da Restauração (1640) e da luta pela retomada da soberania da corte em Lisboa, defendeu uma política de tolerância para os judeus, devido à necessidade de capitais na economia portuguesa. ${ }^{30}$

Para D. Luís, "o procedimento da Inquisição, em lugar de extirpar o judaísmo, o multiplica" e ainda "faz sair de Portugal a gente mais própria para seu comércio". Alguns "remédios" são propostos: a adoção das etapas processuais utilizadas nos tribunais régios, a obrigação de os bens confiscados serem restituídos aos herdeiros dos réus e, finalmente, um perdão geral sucedido pela decisão de "dar aos judeus a liberdade de consciência". ${ }^{31}$

A melhora da exploração do território e o fomento do crescimento da população produtiva deveriam ser acompanhados por uma nova política de alianças e pelo fortalecimento do poderio militar da Coroa. Nas questões militares, D. Luís defendia a formação de uma esquadra de guerra e de uma marinha mercante, para a nacionalização efetiva do comércio ultramarino e para a defesa do Império. O Exército, por sua vez, deveria ser profissionalizado, para que pudesse garantir, ao menos, a defesa do Reino e dos territórios ultramarinos. Esses objetivos só seriam realizados em longo prazo. Enquanto não se chegasse a tal estruturação, não havia meios de fugir da aliança inglesa e do apoio de sua marinha de guerra. ${ }^{32}$

tal o prejuízo que se faz à república." Cf. CUNHA, 2001, p. 224.

29 "A terceira sangria é mais perigosa para o corpo do Estado que as precedentes; porque sendo o Santo Ofício o sangrador, não há quem ouse pôr-lhe as ataduras: e assim é necessário que se deixe esvair o sangue e perca toda a substância, que são como digo, os homens que, com medo da Inquisição, estão todos os dias saindo de Portugal com os seus cabedais, para irem enriquecer os países estrangeiros." Cf. CUNHA, 2001, p. 235.

30 "Por todos os reinos e províncias da Europa está espalhado grande número de mercadores portugueses, homens de grandíssimos cabedais, que trazem em suas mãos a maior parte do comércio e riquezas do mundo. Todos estes (...) estão desejosos de poderem tornar para o Reino e servirem a Vossa Majestade com suas fazendas, como fazem aos reis estranhos" (SILVA apud CUNHA, 2001, p. 155).

31 A liberdade de consciência não deveria ser limitada aos judeus de origem portuguesa: "dando-se, porém, licença aos judeus não batizados, e por consequência estrangeiros, para que fossem estabelecer em Lisboa com a liberdade de terem uma sinagoga." Exceção feita aos judeus "tudescos", "porque supõem que eles descendem do sangue vil do povo que saiu de Jerusalém, depois que Tito Vespasiano destruiu aquela santa cidade, e se vieram estabelecer em Alemanha, além de que são grandes usureiros, e costumados a comprarem tudo o que se furta, e por isso prejudiciais à república". Cf. CUNHA, 2001, p. 262.

32 Cf. CUNHA, 2001, p. 273-276. 
Se a riqueza é resultado da circulação dos bens, o comércio é a chave da prosperidade das nações. Ao identificar os obstáculos ao fortalecimento do comércio português, D. Luís demonstra os limites de suas ideias. Uma leitura apressada mostra um reformador disposto a arcar com as consequências de uma mudança social mais profunda: mera ilusão. Sua primeira sugestão para aumentar a prosperidade do comércio é a reforma dos abusos dos privilegiados, "porque os tributos e encargos de que estes são isentos carregam sobre os mesmos povos e, por consequência, prejudicam a fazenda real". Em destaque estavam os familiares do Santo Ofício, homens que ganhavam distinção por irem "prender quatro miseráveis judeus, se é que o são" e nada mais queriam do que ser reputados cristãos-velhos. D. Luís não aprofunda a discussão em torno dos privilégios tributários da nobreza e do clero. Sua posição como homem do Antigo Regime fica nítida em duas de suas sugestões: a elevação de famílias nobres a Casas de Primeira Nobreza, assim seus membros estariam aptos assumir o governo das províncias do Reino e das conquistas; ${ }^{33}$ e a reorganização das ordens honoríficas, com a valorização da Ordem de Cristo, que, entre as portuguesas, tinha o maior prestígio internacional, de forma a não trivializar sua atribuição.

Outras medidas em busca do equilíbrio da balança comercial são propostas por D. Luís, entre elas uma renovação das pragmáticas sobre o luxo. Para o autor, há uma divisão entre o "luxo profano" e o "luxo devoto". O profano é aquele que acompanha as modas, "que pode contentar a ambição ou loucura dos homens", moldando novos padrões de consumo, em que os gostos da alta aristocracia passam a ser referência para a sociedade. Essa espécie de luxo não poderia trazer benefícios ao Reino: seus bens eram produzidos no exterior - geralmente na França - e oneravam as importações. ${ }^{34}$

33 Nuno Gonçalo Monteiro defende que o estabelecimento de uma política governativa imperial pela Coroa harmonizou a hierarquia política dos espaços ultramarinos com a qualidade social dos nomeados para seus diversos governos. A qualidade de nascimento dos nomeados traduzia as oscilações do valor e da importância que a Coroa e a nobreza titulada atribuíam a cada capitania. Além disso, a nomeação de governadores reinóis e tão nobres quanto fosse possível tinha por objetivo dar o comando a indivíduos de mérito incontestável e que pairassem acima das disputas políticas locais. Cf. MONTEIRO, 2005, p. 191-252.

34 Como bem lembrou Abílio Diniz Silva, a crítica ao consumo de luxo já estava presente no pensamento econômico português na obra de Duarte Ribeiro de Macedo (1618-1680). Macedo não considerava o luxo um mal em si, caso seus bens de consumo fossem produzidos no Reino. "Se todas as manufaturas e fazendas que consome o uso mal regulado dos vestidos e adornos das casas são obrados no Reino, nele fica o custo delas, repartido por tantas mãos quantas são as por onde correram aquelas fazendas até a tenda do mercador; porém, se são obras estrangeiras, lá vai parar o dinheiro, e lá sustenta aquele número de gente, com a riqueza que pudera ficar no Reino. Em um Reino rico e com artes, não só é útil aquele apetite, ainda 
O "luxo devoto", por sua vez, era pernicioso, pois, além de limitar o meio circulante do Reino, dele "nasce que o ouro que se perde em dourar tanto pau, deixa de circular entre o povo, que pagaria as coisas pelo seu justo preço". ${ }^{35}$ Além disso, essa segunda espécie de luxo também restringia o crédito necessário para dinamizar a economia. Nesse ponto do raciocínio, D. Luís criticou outra instituição presente por todo o Império português: a Santa Casa de Misericórdia. Irmão ausente da Casa de Lisboa, o diplomata defendia o bom costume de dar esmolas e o cuidado com os mais necessitados. O problema era, no entanto, o péssimo hábito dos que acreditavam que más ações seriam perdoadas àqueles que dessem esmolas substantivas à instituição e o empate de capitais nos cofres das Misericórdias. ${ }^{36}$

Outro aspecto da devoção portuguesa não passou incólume ao olhar crítico de D. Luís: o número excessivo de festividades e feriados religiosos. O objetivo da crítica é combater a ociosidade, "porque a ociosidade, sobre ser contrária ao bom governo, é mãe de todo vício". Era um "luxo" sacrificar dois terços dos dias do ano em contrição e demonstrações públicas de fé. Era aceitável que os homens participassem das festividades e acompanhassem suas missas, desde que o resto do dia fosse ocupado com atividades produtivas. Flertando com a heresia, D. Luís cita o exemplo dos países protestantes, que guardavam apenas os domingos e o período da Páscoa. Nesses países, o respeito ao trabalho produtivo e a condenação da ociosidade aumentavam a riqueza do Estado e não desviavam os fiéis do caminho da retidão. ${ }^{37}$

que seja imoderado, de vestir custosamente e adornar ricamente as casas, mas é necessário e conveniente." Cf. MACEDO, 1974, p. 203-204. Para as polêmicas em torno da economia do luxo em Portugal, cf. CARDOSO, 1997, p. 81-99.

35 CUNHA, 2001, p. 286.

36 "A segunda, é a da Santa Casa Misericórdia, de que sou irmão, pelos grandes benefícios que dela recebe todo o povo, e pelo grande zelo com que os seus Irmãos praticam os seus institutos e governam as suas rendas, respirando tudo a devoção e caridade. Mas quisera que se evitasse o abuso de que os homens imaginem que ficam restituindo o que furtam a Pedro e a Paulo, logo que deixam os seus bens à Misericórdia, ou a qualquer outra devota ou religiosa corporação. Mas já que por este modo tem a dita irmandade feito um grande fundo [de dinheiro], seria útil que sobre ele se estabelecesse, como em Roma, um Monte de Piedade, ou Lombardo, como se pratica nas cidades de Holanda, e que seria de grande socorro para os que têm alguns efeitos de que se podem servir pronta e secretamente, sem se irem envergonhar com algum usureiro; de sorte que a mesma irmandade lucraria muito, para assistir aos pobres que não tivessem que empenhar." Cf. CUNHA, 2001, p. 286-287. Sobre a importância da assistência e da função institucional das Santas Casas de Misericórdia no Império português, cf. BOXER, 2002, p. 286-308.

37 "E esta é outra vantagem que os países protestantes fazem aos católicos romanos, porque neles só se guardam os domingos, e as quatro Páscoas. Mas como V.a S.a o sabe, e eu o direi, 
Uma solução para o "luxo profano" era retomar a política manufatureira do reinado de D. Pedro II (1667-1706). Capitaneado por D. Luís de Menezes, $3^{\circ}$ Conde de Ericeira (1632-1690), esse esforço tentou reequilibrar as finanças públicas em uma conjuntura de crise. A Coroa portuguesa sacava do comércio colonial e dos direitos cobrados nas alfândegas parcela significativa das suas receitas, o que tornou trágica para o Estado a redução das trocas comerciais e a baixa dos preços das mercadorias portuguesas durante o último quartel do século XVII. Além da crise internacional, as despesas da Guerra de Restauração (1641-1668) resultaram na falta de moeda - decorrência dos gastos no conflito -, no aumento das importações e na diminuição do fornecimento de prata da América espanhola. ${ }^{38}$

A diminuição dos rendimentos do Estado, combinada com a falta de meios de pagamento no cenário internacional, levou a Coroa a decidir por uma reforma monetária baseada na desvalorização e em um novo processo de cunhagem. O problema era o déficit incontornável das importações de manufaturados e de alimentos, além da necessidade de abastecimento da cidade de Lisboa. ${ }^{39}$

Nesse contexto, surgiram as primeiras pragmáticas e textos de autores como Duarte Ribeiro de Macedo defendendo a instauração de manufaturas no Reino para substituir as importações e equilibrar a balança comercial. Um dos setores mais fortalecidos pelo apoio estatal foi o de lanifícios, item que pesava no resultado do déficit. Da mesma forma, a produção de panos de linho era difundida por diversas regiões do país e, tradicionalmente, tinha parte no abastecimento do Reino e do Império. Novas unidades fabris receberam o beneplácito régio e foram instaladas em regiões com tradição

indo de manhã e de tarde à igreja, ouvir a palavra de Deus pela boca dos seus pregadores, que lhes explicam pura e simplesmente o texto que tomam do Evangelho, e os ouvintes de ambos os sexos os leem com grande atenção, sem que os predicantes lhe ajuntem conceitos ou hipérboles; nem trocam as Escrituras para provarem os seus tais ou quais pensamentos, que é uma grande ofensa que se faz à palavra divina; e nós nos contentamos de ouvir devotamente uma missa, que nos parece larga se passa de uma meia hora. E como celebram as quatro Páscoas? Também o direi. Recolhendo-se as suas casas, para nelas examinarem as suas consciências e comungarem, segundo a sua herética crença, quando nós apenas o fazemos na Páscoa da Ressurreição, por satisfazer no exterior ao preceito da Igreja, com medo da excomunhão, que eles não temem. Deus santificou somente os sábados, que são hoje os nossos domingos, como dias de descanso, depois de haver trabalhado nos mais, ainda que com um só Fiat na admirável composição do universo, e não para que abusemos desta ociosidade, como praticamos; antes o louvemos desta sua incompreensível obra, e mereçamos, se é que podemos merecer, a sua infinita misericórdia" (CUNHA, 2001, p. 289).

38 Cf. PINTO, 1979, p. 1-38; Cf., também, PEDREIRA, 1994, p. 21-63.

39 CF. PEDREIRA, 1994, p. 23-24. 
no ofício e com grande disponibilidade de matéria-prima (Serra da Estrela e Alentejo). As manufaturas consideradas "centrais" ficaram na Covilhã e em Estremoz. ${ }^{40}$

Ao elogiar a política manufatureira do século anterior, D. Luís da Cunha mostrava-se cético ao Tratado de Methuen (1703). Assim, as vantagens políticas do pacto eram evidentes, já as econômicas nem tanto. A proteção da esquadra inglesa e a legitimidade fornecida pela aliança com ingleses, austríacos e holandeses, resguardavam Portugal do avanço francês sobre o trono espanhol. O problema, segundo o diplomata, era a inconsistência do argumento defendido pelos produtores e tecelões ingleses: a entrada de vinhos portugueses na Inglaterra deveria ser compensada com a saída de tecidos britânicos em condições recíprocas. Em sua análise, as consequências dessa política e da suspensão da pragmática que protegia as manufaturas de tecido do Reino foi o aprofundamento do déficit no saldo comercial português. ${ }^{41}$

A retomada da prosperidade econômica não seria, no entanto, resultado do equilíbrio das desvantagens frente aos vizinhos espanhóis, da aliança inglesa, da estabilidade das finanças estatais, de uma visão mais pragmática da vida religiosa e da tolerância com os judeus e seus capitais. Assim, para Portugal estabelecer-se como potência de primeira grandeza era necessário ter o controle efetivo das riquezas do Império. D. Luís é explícito

40 Jorge Pedreira faz duas observações importantes: "O fomento manufatureiro - atribuído ao conde de Ericeira e, por vezes, também ao marquês de Fronteira, mas que em parte lhes é anterior - elegeu os setores que ou tinham uma importância fulcral para o robustecimento do Estado, ou fabricavam artigos de luxo, de que não era possível privar inteiramente a aristocracia e outros grupos poderosos. Neste conjunto, os lanifícios assumem um lugar excepcional. Constituem o único ramo sujeito à reorganização que produzia para um consumo alargado. As importações de panos de lã formavam um pesado encargo que ajudava a desequilibrar a balança comercial portuguesa e a proporção de panos estrangeiros no consumo, em especial nas grandes cidades, não era certamente insignificante." Além disso, não é correto afirmar que foi apenas o surto manufatureiro que recolocou Portugal no caminho da prosperidade econômica. Segundo Pedreira, "Os indícios de recuperação começam a registar-se desde finais da década de 1680 . A política prosseguida nas esferas comercial e monetária não deixou de favorecer esta recomposição. Contudo, para o mais rápido restabelecimento da situação comercial concorreram, sobretudo, a exploração de novas áreas geográficas e de novos produtos comerciáveis, o reforço do controlo do Estado - garantindo a eficácia dos monopólios -, os incentivos que concedeu ao crescimento das transações e ainda as dificuldades de outras potências europeias, que se digladiavam em guerras de que Portugal conseguiu manter-se afastado". A conjuntura portuguesa ficaria ainda mais favorável na década de 1690, com a descoberta das minas de ouro americanas. Cf. PEDREIRA, 1994, p. 21-63. Os trechos colocados entre aspas estão nas páginas de 28-29 e 32, respectivamente.

41 Cf. CLUNY, 1999, pp. 60-62. 
em sua instrução: "as conquistas que supus ser um acessório de Portugal, eu as tenho pelo seu principal e ainda garantes da sua conservação, principalmente as do Brasil". Estamos diante de uma inversão curiosa: a relação entre Portugal e o seu Império sempre fora posta nos termos de que o Reino, enfraquecido no contexto europeu, deveria proteger suas conquistas da cobiça de potências rivais. Agora, as riquezas dos domínios ultramarinos deveriam reforçar o prestígio português na Europa. ${ }^{42}$

Para que a riqueza de Portugal não gerasse apenas a prosperidade alheia era necessário transformar as conquistas, as possessões e os domínios do ultramar em colônias de fato. O controle mais racional dos recursos da América portuguesa fatalmente levaria a Coroa portuguesa para seu lugar entre as principais potências europeias. ${ }^{43}$

Ainda em suas instruções, D. Luís demonstra ter uma visão global do Império, propondo políticas para os domínios do Oriente e África. Tais políticas deveriam diminuir os gastos da Coroa, liberando recursos para o governo da América. Esse é o objetivo de sua proposta de criação de uma Companhia de Comércio de Índia e África. ${ }^{44}$

Era necessário constituir uma companhia que mantivesse o fornecimento de escravos negros para o Brasil, que abrisse o caminho pela hinterland africana - ligando Angola e Moçambique - e que explorasse as riquezas minerais ali existentes. A mesma companhia deveria substituir os contratadores do tabaco, pois, dessa maneira, a Fazenda Real ficaria segura contra o risco de falência desses e de perda de seu arrendamento. A soma do privilégio do exclusivo seria outra fonte de rendimentos para a Coroa, podendo ser renegociado sempre que o prazo de cessão expirasse.

42 Evaldo Cabral de Mello recorda que o ouro e a prata do México e do Peru foram os patrocinadores da "preponderância espanhola". No entanto, nas palavras do historiador pernambucano, "mas mesmo na dependência dos metais americanos em que se encontrava Madri para suas aventuras imperiais na Europa, o ultramar, embora vital, continuava a ser avaliado como meio, não como fim". Cf. MELLO, 2002, p. 37.

43 FURTADO, 2007, pp. 69-87.

44 Esse projeto seguia a política de emulação dos exemplos de sucesso econômico típica do século XVIII. "Inglaterra e Holanda não são tão conhecidas pelo nome de potências marítimas, por causa da sua situação, quanto pela extensão do seu comércio, com o qual aumentam as suas forças, devendo uma coisa e outra às companhias que formaram." Cf. CUNHA, 2001, p. 299. Ressaltamos que Abílio Diniz Silva reproduz no apêndice documental de sua edição crítica das Instruções políticas um "Projecto de D. Luís da Cunha para se formar uma companhia de comércio" redigido em 1725. Trata-se do que o projeto da Cia. de Comércio de Índia e África. Cf. CUNHA, 2001, p. 407-421. Existe uma cópia manuscrita do projeto na Coleção Linhares da Biblioteca Nacional do Rio de Janeiro. BNRJ, Divisão de Manuscritos, Coleção Linhares, ms. I - 29, 18,11. 
Em relação ao Oriente, "a primeira utilidade desta companhia seria poupar a Sua Majestade a despesa que faz em sustentar o Estado da Índia, que dizem exceder muito ao lucro que dela tira". Os navios da companhia, montados no Reino, serviriam não apenas para o esforço de defesa dos domínios orientais, mas também distribuíram seus produtos nos mercados do norte da Europa. O capital para todo o negócio seria levantado entre a comunidade de cristãos-novos exilados e, até mesmo, em grupos mercantis de outros Reinos. ${ }^{45}$ Tudo dependeria do apoio régio à empreitada, compromisso que seria estabelecido com a extinção da Casa da Índia e do Juiz da Índia e Mina, podendo os futuros litígios ser da alçada do juízo cível. Isso demonstraria que a Coroa não era a única parte interessada nesse trato. ${ }^{46}$

Já no que diz respeito à América portuguesa, - o Brasil de D. Luís -, a expansão da economia deveria basear-se no trabalho, no comércio e no aprimoramento da fiscalização. $O$ trabalho não ficaria apenas a cargo da mão de obra escrava nas grandes propriedades, mas contaria também com a entrada de estrangeiros aptos a desenvolver outras culturas além do açúcar e do tabaco, como o benefício do cacau, da baunilha, da cochonilha e do índigo, por exemplo. A diversificação da produção é tida, então, como elemento fundamental para a prosperidade do comércio. Sendo assim, os estrangeiros e os portugueses natos embarcados rumo ao Brasil deveriam ter a entrada dificultada na região das minas. Essa política deveria ser acompanhada de medidas contra o risco de revolta dos escravos. ${ }^{47}$

Outra questão importante era a má arrecadação do quinto do ouro. Um tema delicado, pois mexia com os interesses e a lealdade dos vassalos ame-

45 "Por isso supus ser absolutamente necessário que se desse permissão aos judeus para se estabelecerem em Portugal, com inteira liberdade de praticarem os ritos de sua religião, na forma que deixo apontado; porque além das utilidades de que já falei, meteriam na companhia os seus cabedais, e o que mais é, a sua indústria; e visto que melhor que todos entendem o negócio, e com o seu exemplo os de Inglaterra e Holanda, e os mesmos estrangeiros comprariam muitas ações, o que tudo faria entrar no reino grossas somas." Cf. CUNHA, 2001, p. 324.

46 D. Luís defendia o investimento da Coroa na nova companhia com o intuito de atrair novos acionistas, que, futuramente, tornar-se-iam os controladores do negócio. "(...) apontados obstáculos, sendo o maior o da nossa pobreza, e o da nossa pouca indústria, ou para melhor dizer, pusilanimidade dos nossos comerciantes; deveria ser a corte quem os animasse a estas empresas, concorrendo com parte do que necessitassem, para lhes dar princípio, visto que eles não ousam arriscar alguma parte dos seus limitados cabedais, em tudo o que lhes parece novo, costumados ao rego vai, rego vem, de mandar ao Brasil as fazendas que os Ingleses, Holandeses, Franceses, e Hamburgueses lhes confiam para lhes pagar com a volta das frotas; de sorte que o maior lucro fica na mão dos estrangeiros." Cf. CUNHA, 2001, p. 327.

47 CUNHA, 2001, p. 346-347. 
ricanos. A passagem das instruções que trata desse ponto é bastante interessante. Nela, D. Luís relata um diálogo com um judeu nascido no Rio de Janeiro. Segundo o exilado carioca, o problema da arrecadação estava nas casas onde "se quintava" o ouro. Ali reinava a corrupção entre os funcionários régios, sempre dispostos a não registrar parcela do metal apresentado. A solução seria, então, aplicar o quinto não no metal precioso extraído e apresentado, mas nos produtores individualmente. ${ }^{48} \mathrm{D}$. Luís mostrou-se cético em relação à proposta, pois quanto maior fossem os ganhos da Coroa menor seriam os lucros dos mineiros. Todo cuidado era pouco ao lidar com os povos das Minas, "gente tão ambiciosa e de tão maus princípios", sempre no limiar da revolta. ${ }^{49}$

É preciso ressaltar que esse é um dos poucos tópicos nos quais D. Luís se escusa de dar uma opinião, de elaborar um projeto. Ao lidar com a questão da tributação, o diplomata chegou àquele que seria o grande dilema de uma geração futura de reformadores portugueses: como é possível um pequeno Reino controlar um território mais vasto e mais rico sem expor os nexos de sua dominação? Como extrair a riqueza americana para gerar a prosperidade de Portugal sem levantar resistência? Era necessário estreitar os laços entre ambos os territórios, pois o rei "para poder conservar Portugal necessita totalmente das riquezas do Brasil e de nenhuma maneira das de Portugal, que não tem, para sustentar o Brasil"..$^{50}$

Um novo modelo de interdependência econômica entre as partes do Império era a resposta ao dilema. Para isso, era necessário desenvolver a economia do Reino, fortalecendo seus mercadores, incentivando as práticas mercantis e remunerando com mercês aqueles que investissem no comércio imperial.

48 "Ao que me respondeu que esta desigualdade procedia da má arrecadação dos quintos que se lhe pagavam, porque nas casas onde o ouro se quintava, ou para melhor dizer onde se furtava, era sem dúvida que os que traziam, por exemplo, duas arrobas de ouro, não lhe quintavam os oficiais mais que uma, deixando-lhe, por certo proveito que lhe dava, passar por alto a outra; e que para se evitar este abuso e ladroíce, seria necessário não quintar o ouro, mas sim as pessoas que o tiravam (...)." Cf. CUNHA, 2001, p. 344.

49 CUNHA, 2001, p. 345-346. As revoltas originadas por críticas ao arrocho fiscal foram numerosas na América portuguesa. O diplomata tinha conhecimento delas e do ocorrido nas Minas no ano de 1720. Cf. FIGUEIREDO, 2001, p. 197-254. Para o caso específico do levante dos mineiros em 1720, ver o estudo crítico de SOUZA, 1994, p. 13-58.

50 Em uma situação limite, D. Luís propõe a transferência da Corte para o Rio de Janeiro, pois com as riquezas da América o rei poderia montar um grande império distante das disputas europeias. A citação correspondente está em CUNHA, 2001, p. 371. 


\section{Considerações finais}

O projeto de D. Luís marcou o início do uma grande estratégia para o Império. Sem abandonar ideias presentes em autores portugueses do século anterior e respeitando os limites do sistema de remuneração por mercês tradicional da sociedade portuguesa, o diplomata estabeleceu uma pauta de mudanças que seria uma referência para os reformadores que o sucederam.

Por que podemos falar em uma grande estratégia? As primeiras décadas do século XVIII não são apenas um período de aumento das tensões internacionais, mas também a ocasião na qual Portugal passa a ter meios de planejar seu futuro, seja financiado pelo ouro do Brasil, seja pelos recursos poupados por sua política consciente de neutralidade europeia. Nesta oportunidade, a Coroa portuguesa abandonou a participação ativa nos conflitos armados europeus e adotou uma política de neutralidade que perduraria, com breves momentos de disputa com os vizinhos espanhóis, por quase todo o século. D. Luís da Cunha articula em suas Instruções um plano baseado na leitura das dificuldades que o Império português encontrava e enfrentaria em um cenário internacional com outros poderes e centros políticos mais fortalecidos. Seu problema era estabelecer um plano de ação, um curso, para que Portugal pudesse sobreviver em um contexto muitas vezes hostil.

Também podemos perceber uma estratégia no fato de que a partir dos escritos de D. Luís da Cunha a economia política tornou-se uma ferramenta de percepção da realidade econômica e um instrumento de viabilização de um projeto de reformas. O Império será pensado não com a ideia de conquista, expansão da fé e outras características do ideário da expansão ultramarina dos séculos XV e XVI, mas a partir de uma perspectiva utilitária basicamente econômica.

Apostando na centralidade econômica do Brasil, com a riqueza de suas minas, a diversidade de sua produção agrícola e suas infinitas possibilidades comerciais, D. Luís imaginava um futuro em que a monarquia não fosse ameaçada pelo temor de uma nova União Ibérica, onde os interesses comerciais britânicos não teriam primazia sobre os dos vassalos portugueses e a totalidade do Império poderia se inserir de forma mais próspera no concerto das nações. 


\section{Referências}

ARMITAGE, David. The ideological origins of the British Empire. Cambridge: Cambridge University Press, 2009. (Ideas in Context; 59).

BOXER, Charles. O Império Marítimo português (1415-1825). São Paulo: Companhia das Letras, 2002.

CARDOSO, José Luís. Pensar a economia em Portugal: digressões históricas. Lisboa: Difel, 1997.

CARNEIRO, Ana; SIMÕES, Ana; DIOGO, Maria Paula. Enlightenment science in Portugal: The estrangeirados and their communication networks. Social Studies of Science, v. 30, n. 4, p. 591-619, Aug. 2000. Disponível em: <http://www.jstor.org/stable/285782>. Acesso em: 03 maio 2011.

CLUNY, Isabel. D. Luís da Cunha e a ideia de diplomacia em Portugal. Lisboa: Livros Horizontes, 1999.

CORTESÃO, Jaime. Alexandre de Gusmão e o Tratado de Madrid. São Paulo: IMESP, 2006. (Tomos I e II).

COSTA, Fernando Dores. A Guerra da Restauração (1641-1668). Lisboa: Livros Horizonte, 2004.

CUNHA, D. Luís. Instruções políticas. Introdução, estudo e edição crítica por SILVA, Abílio Diniz. Lisboa: Comissão Nacional para as Comemorações dos Descobrimentos Portugueses, 2001.

DANTAS, Vinícius. La privanza del conde de Castelo Melhor y la justificación del valimento en el Portugal restaurado (1662-1667). UNED. Espacio, Tiempo y Forma. Série IV, História Moderna, t. 25, pp. 171-186, 2012.

DUMONT, Louis. Homo aequalis: gênese e plenitude da ideologia econômica. Bauru / SP: EDUSC, 2000.

ELIAS, Norbert. A sociedade de corte: investigação sobre a sociologia da realeza e da aristocracia de corte. Rio de Janeiro: Jorge Zahar, 2001.

ELLIOTT, John Huxtable. Richelieu and Olivares. Cambridge: Cambridge University Press, 1984.

ELLIOTT, John Huxtable. El conde-duque de Olivares: el politico en una época de decadencia. Barcelona: Crítica, 2008. (Biblioteca de Bolsillo).

FIGUEIREDO, Luciano Raposo de Almeida. O Império em apuros. Notas para o estudo das alterações ultramarinas e das práticas políticas no Império Colonial Português, séculos XVII e XVIII. In: FURTADO, Júnia Ferreira (Org.). Diálogos Oceânicos: Minas Gerais e as novas abordagens para uma história do Império Ultramarino Português. Belo Horizonte: Editora UFMG, 2001, p. 197-254.

FURTADO, Júnia Ferreira. Dom Luís da Cunha e a centralidade das Minas auríferas brasileiras. Anais de História de Além-Mar, v. VIII, 2007, pp. 69-87.

FURTADO, Júnia Ferreira. O oráculo que S. Majestade foi buscar: D. Luís da Cunha e a geopolítica do novo império luso-brasileiro. In: FRAGOSO, João Fragoso; GOUVEA, Maria de Fátima (Org.). Na trama das redes: política e negócios no Império português, séculos XVI-XVIII. Rio de Janeiro: Civilização Brasileira, 2010, p. 373-400. 
HECKSCHER, Eli Filip. La época mercantilista: historia de la organización y las ideas económicas desde el final de la Edad Media hasta la Sociedad Liberal. 1. reimp. México: Fondo de Cultura Económica, 1983.

HIRSCHMAN, Albert. As paixões e os interesses: argumentos políticos a favor do capitalismo antes de seu triunfo. Rio de Janeiro: Record, 2002.

HONT, Istvan. Jealousy of trade: International competition and the Nation-State in historical perspective. Cambridge, Massachusetts / London, England: The Belknap Press of Harvard University Press, 2005.

HONT, Istvan; IGNATIEFF, Michael (Ed.). Wealth \& Virtue: The shaping of political economy in the Scottish Enlightenment. Cambridge and New York: Cambridge University Press, 1983.

LOUREIRO, Marcelo. "A pedra fundamental deste edifício": o governo por conselhos na monarquia portuguesa do pós-Restauração. Revista 7 Mares, n. 5, pp. 44-57, dez. 2014.

LUTTWAK, Edward N. The Grand Strategy of the Roman Empire. From the First Century A. D. to the Third. Baltimore and London: The Johns Hopkins University Press, 1976.

LUTTWAK, Edward N. The Grand Strategy of the Byzantine Empire. Cambridge, Massachusetts: The Belknap Press of Harvard University Press, 2009.

MACEDO, Duarte Ribeiro de. Sobre a introdução das artes (1675). In: SÉRGIO, Antonio. Antologia dos economistas portugueses (século XVII). Lisboa: Livraria Sá da Costa Editora, 1974, p. 203-204.

MAGNUSSON, Lars. Mercantilism: The shaping of an economic language. London and New York: Routledge, 1994.

MELLO, Evaldo Cabral de. Um imenso Portugal: história e historiografia. São Paulo: Editora 34, 2002.

MIRANDA, Tiago dos Reis. Estrangeirados: a questão do isolacionismo português nos séculos XVII e XVIII. Revista de História, São Paulo, n. 123-124, ago./jul., 1990/1991, p. 35-70.

MONTEIRO, Nuno Gonçalo. Identificação da política setecentista. Notas sobre Portugal no início do período joanino. Análise Social, v. XXXV (157), pp. 961-987, 2001.

MONTEIRO, Nuno Gonçalo; CARDIM, Pedro; CUNHA, Mafalda Soares da (Org.). Optima Pars. Elites Ibero-Americanas do Antigo Regime. Lisboa: Imprensa de Ciências Sociais, 2005. (Estudos e Investigações, 36).

ORMROD, David. The rise of commercial empires: England and the Netherlands in the Age of Mercantilism, 1650-1770. Cambridge: Cambridge University Press, 2003.

PARKER, Geoffrey. The Grand Strategy of Philip II. New Haven and London: Yale University Press, 2000. (Paperback Edition).

PARKER, Geoffrey. The Military Revolution: Military innovation and the rise of the West. (1500-1800). $2^{\text {nd }}$ Ed. Cambridge: Cambridge University Press, 2003.

PEDREIRA, Jorge Miguel Viana. Estrutura industrial e mercado colonial. Portugal e Brasil (17801830). Lisboa: Difel, 1994.

PINTO, Virgílio Noya. O ouro brasileiro e o comércio anglo-português. 2. ed. São Paulo: Editora Nacional, 1979.

POCOCK, John Greville Agard. The political limits to premodern economics. In: DUNN, John 
(Ed.). The economic limits to modern politics. Cambridge: Cambridge University Press, 1999. (Murphy Institute Studies in Political Economy), p. 121-141.

POCOCK, John Greville Agard. The Machiavellian Moment: Florentine political thought and the Atlantic Republic tradition. $2^{\text {nd }}$ ed. Princeton and Oxford: Princeton University Press, 2003. (Paperback Edition).

SCHABAS, Margaret. The natural origins of Economics. Chicago: The University of Chicago Press, 2005.

SCHAUB, Jean Frédéric. Portugal na monarquia hispânica (1580-1640). Lisboa: Horizonte, 2001.

SILVA, Abílio Diniz. Gênese, estrutura e principais temas das Instruções políticas. In: CUNHA, Luís da. Instruções políticas. Introdução, estudo e edição crítica por SILVA, Abílio Diniz. Lisboa: Comissão Nacional para as Comemorações dos Descobrimentos Portugueses, 2001, p. 155.

SOUZA, Laura de Mello. Discurso histórico e político sobre a sublevação que nas Minas houve no ano de 1720. Estudo crítico, estabelecimento do texto e notas. Belo Horizonte: Fundação João Pinheiro. Centro de Estudos Históricos e Culturais, 1994. (Coleção Mineiriana. Série Clássicos).

Testamento Politico de D. Luís da Cunha (1748). São Paulo: Editora Alfa-Ômega, 1976. (Série Testemunhas da História, v. 1).

VIEIRA, Antônio. Escritos históricos e políticos. Organização de Alcir Pécora. São Paulo: Martins Fontes, 1995.

WALLERSTEIN, Immanuel. O sistema mundial moderno. O mercantilismo e a consolidação da economia-mundo europeia (1600-1750). Porto: Edições Afrontamento, 1994. (Biblioteca das Ciências do Homem / História-12). v 2.

WENNERLIND, Carl. Casualties of Credit. The English Financial Revolution (1620-1720). Cambridge, Massachusetts: Harvard University Press, 2011.

\section{Sobre os autores}

Nelson Mendes Cantarino-nelsonmc@unicamp.br

Professor de História Econômica no Instituto de Economia, Universidade Estadual de Campinas, Campinas, SP, Brasil. ORCID: https://orcid.org/0000-0001-6878-4479.

Fernando Ribeiro Leite Neto-fernandorln@insper.edu.br Professor no Instituto de Ensino e Pesquisa (INSPER), São Paulo, SP, Brasil. ORCID: https://orcid.org/0000-0001-7932-3440.

Nelson Mendes Cantarino agradece à Fundação de Amparo à Pesquisa do Estado de São Paulo (FAPESP). Este artigo é resultado parcial do projeto associado ao auxílio à pesquisa processo n 2018/04642-0.

\section{Sobre 0 artigo}

Recebido em 12 de julho de 2018. Aprovado em 01 de junho de 2019. 